\title{
Future compatibility of district heating in urban areas - a case study analysis in the context of integrated spatial and energy planning
}

\author{
Peter Lichtenwoehrer ${ }^{1}$, Susanna Erker ${ }^{1 *}$ D, Franz Zach ${ }^{2}$ and Gernot Stoeglehner ${ }^{1}$
}

\begin{abstract}
Background: District heating is widely used for thermal energy supply and offers a broad range of benefits like the possibility to integrate decentral heat supply technologies or to foster the utilisation of renewable energy sources. Thus, district heating has the potential to gradually contribute to a more sustainable thermal energy supply and to consequently facilitate the energy turn. However, due to specific requirements of this technology, strategic planning is required for the successful implementation of district heating networks. Previous research mainly focuses on either economic, environmental, or technological aspects of district heating. This study therefore aims to execute a comprehensive assessment of district heating systems in the following four sections: (1) integrated spatial and energy planning, (2) costs, (3) resources and (4) environment and climate.
\end{abstract}

Methods: To this end, the recently developed Eco.District.Heat kit (EDHk) is used to evaluate and rate eight case studies consisting of 14 different urban typologies, while considering the aforementioned sections of interest. The paper applies the EDHk to assess different spatial structures and grid configurations as well as a broad mix of different thermal energy sources.

Results: With regard to integrated spatial and energy planning (section 1), the assessment shows heterogenous ratings whereas the case studies exhibit quite constant positive ratings with regard to costs (2), environment and climate (4). Although a lot of material is used for the construction of networks (i.e. resources, section 3), the question whether or not to dismantle old grids for resource utilisation cannot be answered definitely. According to our results, future development scenarios in the context of climate change and building renovation until 2050 have little influence on the final ratings.

Conclusions: Based on the comprehensive assessment of eight case studies, it can be concluded that district heating systems offer a long-term and sustainable solution of heat supply for different spatial archetypes and types of urban fabrics. Furthermore, the proposed methodology allows users to critically examine planned projects and to detect shortcomings at an early planning stage. The EDHk thus provides a suitable methodology to support strategic decisions in integrated spatial and energy planning.

Keywords: District heating, Spatial planning, Climate change, Energy planning, Qualitative and quantitative assessment, Strategic decision-making tool

\footnotetext{
* Correspondence: susanna.erker@boku.ac.at

${ }^{1}$ Institute of Spatial Planning, Environmental Planning and Land

Rearrangement, University of Natural Resources and Life Sciences, Vienna,

Peter-Jordan-Straße 82, 1190 Vienna, Austria

Full list of author information is available at the end of the article
}

(c) The Author(s). 2019 Open Access This article is distributed under the terms of the Creative Commons Attribution 4.0 International License (http://creativecommons.org/licenses/by/4.0/), which permits unrestricted use, distribution, and reproduction in any medium, provided you give appropriate credit to the original author(s) and the source, provide a link to the Creative Commons license, and indicate if changes were made. 


\section{Background}

One of the great challenges of the twenty-first century is global warming. Only a continuous reduction of greenhouse gas emissions on a global scale will allow to tackle this challenge, as was acknowledged by the recent ratification of the Paris agreement. In this particular agreement, the signatories aim to limit the global average temperature increase below $2{ }^{\circ} \mathrm{C}$ compared to the pre-industrial level by reducing greenhouse gas emissions [1]. Therefore, the use of renewable energy sources (RES) as well as the promotion of energy efficiency measures has to be significantly enhanced. However, efforts have to be measured and quantified in order to understand if promised targets can be reached. For instance, the Climate Change Performance Index offers a global ranking concerning the efforts on climate protection of 56 countries and the European Union [2]. With regard to this index, various European countries are performing relatively poor concerning $\mathrm{CO}_{2}$ emissions or climate policy.

In terms of energy consumption and provision, it is essential to distinguish between thermal energy and electrical energy. In the European Union, approximately half of the final energy is used for thermal energy, including heating and cooling [3]. Thus, measures and options have to be developed in order to guarantee a sustainable thermal energy provision. Depending on the share of RES in the energy supply mix, district heating systems (DHSs) can pose an option to reduce greenhouse gas emissions and to decarbonise the energy system. Yet, conventional non-renewable energy sources like natural gas or fuel oil are widely used, which simultaneously increases the potential for using RES in DHS. Generally, energy transition and a decarbonisation of the energy system strongly depend on the chosen energy source. On a European level, only $12 \%$ of the primary energy supply for heating and cooling are provided by RES. Overall, $45 \%$ of the demand can be allocated to the residential sector, $37 \%$ to industries and $18 \%$ to services. In total, district heating is used to supply around $9 \%$ of the European heating demand. The largest share of this demand is covered by gas (40\%), coal (29\%) and biomass (16\%) [4]. In Austria, the share of renewables used for district heating networks (DHNs) is estimated to be around $46 \%[5]$.

Lund et al. [6] emphasise the advantage of DHNs to support the utilisation of renewable energy sources like geothermal, biomass, waste incineration or excess heat. For comparably small-scale DHNs, supplementary energy sources like solar energy should be considered. By integrating decentralised energy sources, or including prosumers (thermal energy consumers also providing surplus energy into the system), the share of renewable energy source can be additionally increased and simultaneously costs reduced [7, 8]. Apart from benefits of decentral solutions, Persson and Werner [9] estimate a possible heat coverage of district heating in large cities (above one million inhabitants) to be around $80 \%$. Yet, they concurrently argue that due to reduced total thermal energy demand and densities, smaller cities pose significantly lower potential supply rates. Thus, they estimate a potential share of $24 \%$ of district heating for cities with less than 150,000 inhabitants.

However, unlike electricity or natural gas, thermal energy cannot be distributed across large distances. Due to energy loss of transportation, DH can be strictly categorised as a local transportable energy source [10-12]. A low temperature level results in less heat loss compared to higher temperature levels. Furthermore, the overall efficiency of DHNs depends on heat demand densities: energy consumers located in close proximity in addition to high thermal energy demand and mix of function will increase the efficiency of the network [11]. In that sense, areas comprising multi-functional and dense structures are of special interest for district heating. Thus, mix of function affects the temporal patterns of heat demand, so that the difference of base load and peak load can be reduced and full-load hours can be increased. In Austria, mono-functional residential areas need around 2000 full-load hours, whereas multifunctional areas demand 4500 full-load hours and more [13]. Urban, town or village centres serve as examples for such areas suitable for DHS due to comparably high densities and continuous heat demand. Moreover, in multi-functional structures, cascading use of thermal energy is also possible [12]. It is evident that spatial developments play a significant role for the long-term suitability of DHS. By more thoroughly assessing and considering spatial structures, the quality of DHS planning can be raised. In this research, we emphasise integrated spatial and energy planning (ISEP), combining both the spatial dimension of energy demand and the spatial dimension of energy supply [12]. After identifying appropriate thermal energy consumers as well as other potential future heat sinks, the ideal location of DHNs can be determined.

Moreover, during the research project Eco.District.Heat, some interesting challenges were addressed and problems concerning DHNs were discussed. For instance, building refurbishment efforts like thermal insulation might affect the energy demand that possibly leads to uncertainties concerning the long-term suitability of DHNs. Mathiesen et al. [14] conjecture a continuous decrease of heat demand in buildings until 2050 . This can be taken as a holistic assumption for countries requiring heat, not only for Denmark where the study was conducted. Additionally, Loibl et al. [15] refer to strict building regulations resulting in low heat demand for passive houses below $15 \mathrm{kWh} / \mathrm{m}^{2}$ that might lead to 
a sort of a blockade of district heating expansion. Also, Persson and Werner [9] raise increasing concern about the competitiveness of DHNs especially in low-density areas. Therefore, smart and sustainable planning is necessary in order to guarantee the future applicability of DHNs. Another interesting aspect concerning DHNs is the resource input for network constructions. According to the European Commission [16], barriers contradicting resource efficiency should be removed. Also, any kind of waste should be treated as a resource and recycling processes should be increased.

To date, various tools for integrated spatial and energy planning have been developed and introduced to measure, for instance, infrastructure costs of settlements, (embodied) energy demand of whole settlements or energy performance certificates for settlements [17]. Depending on the complexity and objective of the tool, different fields of application arise and thereof a broad variety of results can be generated. Also, detailed energetic assessments of settlement structures have been carried out (e.g. [18, 19]). Additionally, detailed economic evaluations of future economic compatibility of DHNs can be found (e.g. [9]). Likewise, material stock analysis of buildings for whole cities or life-cycle assessments of buildings have been addressed [20,21]. However, a comprehensive and cross-disciplinary kit or approach to assess the long-term applicability of district heating in urban areas was still missing. In addition, Werner [22] urged new methods to be applied and also to increase the awareness in order to underline the benefits of DHNs. Thus, a holistic methodology combining economical, material, energetic and spatial aspects in one kit was developed and documented in Erker et al. [23], the so-called "Eco.District.Heat" kit (EDHk). The aim of this paper is to assess the suitability of DHNs with the EDHk in various case studies (CSs) across Austria in order to address the following questions: What are the main factors influencing the suitability of district heating in urban areas? How are future developments like climate change or building refurbishments influencing the long-term suitability of district heating? In terms of resource utilisation, is a dismantling of discontinued district heating networks reasonable? This paper starts by presenting the methods used for the CS analysis, beginning with a brief description of the EDHk, followed by the selection process and description of analysed CSs. In the "Results" section, a status-quo analysis as well as scenarios for the evaluated CSs is presented. Additionally, options in order to improve the suitability of settlements for district heating are highlighted. Finally, the "Discussion" section tries to answer the questions raised and also critically reviews the applied methodology as well as its suitability for ISEP.

\section{Methods}

The first part of the "Methods" section describes the Eco.District.Heat kit (EDHk). Key elements of the kit as well as basic calculation steps are presented. The second and third segments deal with the selection process and a detailed description of the chosen CSs. CSs were used to allow a first test of the EDHk and to generate results that are subsequently discussed in the light of ISEP.

\section{The "Eco.District.Heat" kit}

During the nationally funded research project Eco.District.Heat (EDH), a cross-disciplinary and holistic kit was developed that is capable of assessing the suitability of district heating networks (DHNs) in urban areas. The EDHk was developed by the Institute of Spatial Planning, Environmental Planning, and Land Rearrangement (IRUB), the Austrian Energy Agency (AEA) and the Resource Management Agency (RMA) and is presented in detail by Erker et al. [23]. Within the same research project and prior to the kit development, a system analysis on DHSs was carried out by including aspects concerning spatial planning, environmental planning, energy technology, building technology and resource management. During the research project and based on the knowledge gained from the system analysis, the final EDHk was developed and is subsequently described, since it is used for the case study analysis. As presented in Erker et al. [23], the kit carries out assessments in four sections: (1) ISEP, (2) costs, (3) resources and (4) environment and climate. In the ISEP section, three sub-analyses are carried out, including an assessment of the thermal energy consumption (summarised with the term "location analysis"), the thermal energy distribution ("grid analysis") and potential thermal energy sources ("heat source analysis") for subareas of a wider urban fabric. In the second section, cost-relevant parameters like the production costs for the energy sources or the connection density of the DHN are considered. The third section estimates amounts of materials used for the construction of buildings in the respective settlements and the DHNs. Finally, based on the previous data input, the kit assesses environmental impacts. Resulting from the status quo analysis, future scenarios concerning climate change or refurbishment rates can also be evaluated. The effects of climate change are estimated by incorporating a reduction of heating degree days until 2050. Concerning refurbishment rates, percentage values can be entered. Regarding potential scenarios, it is noteworthy that within the EDH research project a comprehensive overview of influencing factors on the energy consumption density until 2050 was given. Thus, population growth and housing developments are also included in the scenarios. Finally, the kit presents a qualitative rating for each subarea for the ISEP section (including 
the three sub-analyses of ISEP), the costs section and the environment/climate section. Basically, a settlement can be assembled by several subareas that differ from each other due to certain characteristics. For instance, one subarea of the same settlement can feature a higher building density or a different mix of functions than others. Consequently, the user can specify up to five different subareas. The final results in the EDHk are demonstrated by benchmarked ratings from " $\mathrm{A}$ " to " $\mathrm{D}$ ". In Table 1 the interpretation of those ratings is illustrated.

It is important to note that the final rating can be at the upper margin (close to next higher rating) or at the lower margin (close to next lower rating class). Thus, a more detailed assessment of the input parameters and scenario calculations can reveal if a better rating is achievable or not. Consequently, it can be checked if the rating is stable enough after applying scenario calculations. The final rating in the kit is based on seven scenario queries and 49 queries in the different assessment sections that deliver input parameters to four decision trees interconnecting in total 35 decision matrices. In the following CS description and in the work of Erker et al. [23], additional information and a more detailed method description regarding input parameters and the decision model can be found.

\section{Case study selection}

During the research project, a case study approach was applied to continuously improve the developed EDHk. Simultaneously, the CS application also contributed to generating valuable results that are presented in this paper and are subsequently discussed. In total, eight Austrian CSs were selected for further evaluations. Austria was chosen for the study at hand, due to the quality and availability of essential documents and reports needed for the application of the EDHk. The final application was made possible by the cooperation of energy planning agencies, energy providers and infrastructure providers. Whenever essential information was missing in the documents, involved experts in the research project from the cooperating institutions were consulted.

The selected CSs were chosen because of their diverse characteristics reflecting distinctive heat demands and different spatial features that are briefly described in the following. At the beginning of the selection process, spatial archetypes and their relevance in the energy turn were taken as a basis [12, 24, 25]. Since major potentials for DHS can be assumed in urban areas, the survey was focused on this spatial archetype. However, in order to countercheck the results, two suburban CSs were also included in the analyses. Within these two spatial archetypes, the aim was to ensure a broad variety of spatial characteristics in order to assess the usefulness of the results. Building density and population density as well as mixed use of spatial structures are also known to have a great impact on DHSs. Thus, the following five spatial characteristics were considered in the selection process of the CSs: (1) size of the case study area, (2) construction period of buildings, (3) building typology (for instance terraced houses, multi-storey buildings, etc.), (4) type of use (residential, commercial use and mixed use) and (5) building density (gross floor area/gross development area). Besides spatial aspects, energetic parameters were also embraced for the selection process. Accordingly, in the chosen CSs, either renewable heat sources or a mix of renewable and fossil sources were contemplated. Aside from economic considerations, the environmental impact also profoundly depends on the heat source, so this parameter was considered to be essential for the selection. Furthermore, the temperature level used for the DHNs was taken into consideration, not only from an energetic and spatial perspective, but also from an economic point of view. The final selection was carried out based on the expertise of planning agencies, energy providers and infrastructure providers from which the CSs originate. Finally, the process of data input and evaluation was carried out

Table 1 Interpretation of the rating presented in the Eco.District.Heat kit (own illustration)

\begin{tabular}{ll}
\hline Rating & Interpretation \\
\hline A & - Best achievable rating \\
& - A detailed planning of the DHN can be recommended \\
& - Good preconditions for a successful implementation of a DHN \\
& - Still good preconditions for a successful implementation of a DHN \\
& - By reflecting key parameters, necessary adaptations should be identified in order to gain better results \\
& - After adjustments, detailed planning might be very likely recommended \\
& - Planned DHN should be handled with caution \\
& - A comprehensive analysis at the level of detailed planning is necessary in order to decide if DHN can be implemented \\
& - Problems operating a DHN can be expected \\
& - Worst achievable rating \\
& - Areas with a final D rating are not feasible for the implementation of a DHN \\
& - Severe problems can be expected and contradict a reasonable implementation of a DHN \\
D &
\end{tabular}


Table 2 Main characteristics of the selected case studies for the EDHk application (own illustration)

\begin{tabular}{|c|c|c|c|c|c|c|c|c|}
\hline \multirow[t]{2}{*}{ Characteristics } & \multicolumn{8}{|c|}{ Selected case studies (CSs) } \\
\hline & CSI & CS $\|$ & CS III & CS IV & CS V & CS VI & CS VII & CS VIII \\
\hline Number of subareas & 3 & 1 & 3 & 2 & 1 & 1 & 2 & 1 \\
\hline Spatial archetype & Urban & Urban & Urban & Urban & Urban & Urban & Suburban & Suburban \\
\hline $\begin{array}{l}\text { Gross development } \\
\text { area (ha) }\end{array}$ & 18 & 1 & 64 & 16 & 11 & 26 & 4 & 1 \\
\hline Average density $^{a}$ & $0.5-1.0$ & 2.0 & $1.0-1.5$ & $1.6-1.9$ & $0.9-1.0$ & 1.0 & 0.25 & 0.5 \\
\hline $\begin{array}{l}\text { New/existing } \\
\text { development }\end{array}$ & $\begin{array}{l}\text { New \& } \\
\text { existing }\end{array}$ & Existing & New & New & New & New & New \& existing & New \\
\hline Main building type & Multi-storey & Multi-storey & Multi-storey & Multi-storey & Multi-storey & Multi-storey & $\begin{array}{l}\text { Single-family } \\
\text { houses }\end{array}$ & Terraced houses \\
\hline Utilisation & $\begin{array}{l}\text { Residential } \\
\text { use }\end{array}$ & Mixed use & Mixed use & Mixed use & Mixed use & Mixed use & Residential use & Residential use \\
\hline Heat source for DHS & Renewable & Fossil \& renew & Fossil \& renew & $\begin{array}{l}\text { Fossil \& } \\
\text { renew }\end{array}$ & Fossil \& renew & Fossil \& renew & Renewable & Renewable \\
\hline $\begin{array}{l}\text { Supply temperature } \\
\left({ }^{\circ} \mathrm{C}\right)\end{array}$ & $66-80$ & $66-80$ & $66-80$ & $35-65$ & $35-65$ & $35-65$ & $66-80$ & $66-80$ \\
\hline
\end{tabular}

${ }^{a}$ Corresponds to usable gross floor area (GFA) of buildings per gross development area (GDA)

by the project team and together with external experts involved in the CSs.

\section{Description of applied case studies}

The size of the CSs ranges from 1 ha up to approximately 60 ha. Some of the analysed CSs comprised heterogeneous areas. For example, a study site consisted of both existing settlements and new development areas, so the whole study site was split up into subareas that shared certain common characteristics like similar building typology, construction period of buildings or building density. For instance, CS I and CS III (Table 2) were each split up into three subareas. In general, some of the selected CSs represent residential structures, others indicate a mixed use consisting of residential and commercial areas. Table 2 gives an overview of the main characteristics of the selected CSs. Due to data protection regulations, the exact location and names of the study areas cannot be published.

\section{Results}

The following section is split into three parts. The status-quo results of the CS assessment are followed by an evaluation of future developments and its effects on DHNs. Finally, options on how to optimise spatial structures for implementing DHNs are presented.

\section{Assessment of case studies - status-quo}

In this first section, the current situation (Status-quo) of the CS analysis is presented. Table 3 provides an overview of the final ratings for each CS and its corresponding fields of evaluation, as presented in the EDHk. The first row shows the analyses results of ISEP that is split into three sub-analyses: (1) location analysis, (2) analysis of the supply network and (3) analysis of the used heat sources planned to supply the district heating network. The ISEP assessment is followed by a cost assessment, a resources assessment and an evaluation of environmental and climate-related aspects.

Starting with ISEP, key characteristics leading to the final rating results of the single CSs are presented. In this first part an overview of all A-rated CSs is given. Out of the eight analysed CSs, two (CS I and CS III) are rated $\mathrm{A}$ in the overall ISEP assessment. The final ISEP rating already includes the location analysis, the supply network analysis and the heat sources analysis of all subareas. Final key characteristics of the A-rated CSs are as follows:

- High heat (GWh/ha.a) and connection density (GWh/km.a) values

- Multiple and spatially connected subareas

- Subareas covering up to 34 ha

- Mix of function in certain subareas

- Individual subareas with low building densities (e.g. 0.7 gross floor area (GFA)/gross development area (GDA)) are compensated by neighbouring settlements with high densities

- High degree of connected buildings to the DHN in both existing and new developments

- Sufficient availability of energy sources to cover thermal energy demand of all subareas

Each A- and B-rated CS can be described as typical urban areas with similar characteristics that can be found across Austria and Central Europe. For the two B-rated CSs (CS IV and CS VI), the following common characteristics are identified: 
Table 3 Summary of the case study analysis in four sections (own illustration)

\begin{tabular}{|c|c|c|c|c|c|c|c|c|}
\hline \multirow[t]{2}{*}{ Assessment-section } & \multicolumn{8}{|c|}{ Analysed case studies (CSs) } \\
\hline & CSI & CS ॥ & CS III & CS IV & CS V & CS VI & CS VII & CS VIII \\
\hline (1) ISEP & A & C & A & B & $C$ & B & $C$ & $C$ \\
\hline Location & D & $D$ & B & C & $\mathrm{D}$ & C & D & $D$ \\
\hline Supply network & C & A & C & C & C & C & D & B \\
\hline Heat sources & A & A & A & A & A & A & B & B \\
\hline (2) Costs & A & A & A & A & A & A & B & A \\
\hline (3) Resources & \multicolumn{8}{|c|}{ Quantitative assessment only } \\
\hline (4) Environm. \& Climate & $A$ & B & B & B & B & $B$ & $A$ & $A$ \\
\hline
\end{tabular}

- Multi-storey buildings with high density values up to 1.8 (GFA/GDA)

- Mix of function in certain subareas

- Low-density (GFA/GDA) of CS VI compensated by comparably large development area

- Degree of connected buildings in all subareas at $100 \%$

- Sufficient availability of energy sources to cover thermal energy demand of all subareas

Half of the analysed CSs are rated C and are therefore rather poor examples in terms of ISEP. CS II and CS V are both urban areas, whereas CS VII and CS VIII are suburban. Both urban CSs consist of only one subarea each. CS II is a small isolated historical city block comprising only 1 ha but high-density (GFA/GDA), whereas CS V features low-density (GFA/GDA) and a comparably larger gross development area. CS V indicates significant differences to the other C-rated CSs with only one subarea and a low-density (GFA/GDA). The low rating of this CS is mainly caused by poor spatial quality and inefficient network configurations. Due to the suburban character of the last two CSs (low densities of around 0.3 (GFA/GDA) and houses with bad thermal insulation), it is difficult to compare them with the other six. It can be summarised that amongst all CSs no D rating was detected in the ISEP section. Typical urban development areas comprising multiple subareas gained better ratings than isolated settlement structures in urban settings or CSs with low densities as well as suburban areas, respectively.

Interestingly, seven out of eight CSs reach the best rating in the costs section. In every CS a DHN is either already in operation or planned. There was no CS supplied by both district heating and gas. Such parallel infrastructure would increase the overall costs and lower the rating. In 11 out of 14 subareas, no district heating network has been available so far. Therefore, mainly new networks with state-of-the-art insulation and little heat loss are either planned or were recently built, reducing the overall distribution costs. Simultaneously distribution costs are kept down due to medium to low temperature levels of the heat carrier $\left(<80^{\circ} \mathrm{C}\right)$ and low height differences in the supply area $(<20 \mathrm{~m})$. Some subareas are characterised by a high share of sealed surfaces. Compared to new developments at the outskirts of cities, the share of sealed surfaces is high in existing settlements. Nevertheless, the temperature level, height difference and the sealing of surfaces did not indicate any strong influence on the final ratings in our analyses. In the EDHk methodology, the production costs for the energy source (including all costs up to the feed-in point of the DHN) pose a strong impact on the final rating. However, in the evaluated CSs, production costs are all estimated below five cents per kilowatt-hour. Due to the low production costs, the final rating is not negatively influenced. According to Erker et al. [23], $2 \mathrm{GWh} / \mathrm{km}$ and year of occupancy rate is the threshold for the final A rating in the cost section of the EDHk. In CS VI, the occupancy rate ranges between 0.5 and 0.9 . This is the main reason for pushing the final rating in this particular CS to B. Overall, favourable conditions concerning economic aspects for the establishment of DHNs in the presented CSs are given.

In contrast to the assessment of ISEP, costs as well as environment and climate, no rating for material flows and resource deployment is carried out. In the resource section of the EDHk, quantities (tonnes) of used construction material are calculated. In order to compare different CSs and associated material flows, a comparison between construction material input for buildings and for district heating networks is carried out. Depending on the type of buildings, the utilisation and the construction period, different values for material inputs arise. The pivotal aspect for district heating networks is the pipe diameter from which different quantities of construction material can be calculated. Based on this, proportional values between materials used for buildings and network infrastructure are calculated. Contrary to expectations, a relatively high amount of up to one third of the total construction material can be allocated to district heating networks. Depending on the efficiency of 
the whole district heating network, some CSs show a significantly higher share of pipe lengths resulting in more material use for DHNs. This fits for CS II, CS III and CS VI for which used materials for DHNs make up more than 30\% compared to used materials in buildings. CS IV and CS V exhibit shares between 20\% and 30\%, whereas CS I, CS VII and CS VIII a share lower than $10 \%$.

Finally, not a single CS is rated C or D in the environment and climate section. In fact, three CSs (I, VII and VIII) are rated A. The positive ratings are mainly a result of recently built district heating networks (after the year 2000) and a high share of renewable energy sources (more than 60\%). The main parameter influencing the results of the five B-rated CSs is the share of RES. In the B-rated CSs, the share of renewables is estimated between $20 \%$ and $44 \%$. Also, greater pipe diameters and associated higher energy demand for construction result in the comparative lower ratings of these CSs.

\section{Scenario analysis - developments until 2050}

In the EDHk, the effects of climate change can be estimated, by applying a reduction of heating degree days from now until 2050. After applying a 3\% reduction, the ratings do not change. Starting at $5 \%$, the rating of only one CS (CS I) drops to $\mathrm{C}$ in the ISEP section. The reason in this specific case is the overall reduction of heating demand below $10 \mathrm{GWh} / \mathrm{a}$. Although the total thermal energy demand of the other CSs is reduced, they do not show any volatility to the reduction of heating degree days. Changes in ratings in the other sections except ISEP could not be detected.

In four CSs, the ratings of the ISEP and costs section shift after applying the scenario building refurbishment. In this scenario, the share of refurbished buildings until 2050 can be increased. For example, the ISEP rating of CS I changes to C after applying 10\% refurbished buildings until 2050. Otherwise only minor changes in certain subareas occur, applying 50\% and more building refurbishment. Due to this scenario, the connection density of two CSs is significantly reduced (applying $>40 \%$ ) to below $0.9 \mathrm{GWh} / \mathrm{km} . \mathrm{a}$, diminishing the final cost ratings. A combination of the two scenarios (minus 10\% reduction of heating degree days and $50 \%$ building refurbishment) only reveals an impact on CS III. In this CS, the location analysis rating of the second subarea changes from $\mathrm{C}$ to $\mathrm{D}$. Otherwise, no significant changes due to the combination of these two scenarios are detected.

In addition to the effects of climate change and building refurbishment, the EDHk also embraces settlement developments until 2050. For instance, the predicted population or the future share of residential buildings can be entered. After applying the settlement development scenarios, depending on the degree of adjustments (increase or decrease), the previously estimated heat demand can change significantly. If the heat demand is estimated to increase, additional energy sources have to be identified. Additionally, detailed knowledge about the permitted future building density is required whenever an increase of buildings or densification is anticipated. It is also essential to note that the settlement development scenarios strongly affect the overall ratings.

\section{Optimising and improving the suitability of settlements for district heating}

The following chapter presents possibilities on how to increase the ratings of the analysed CSs. In other words, potentials on how to optimise the suitability of settlements for district heating, by incorporating scenario calculations, are presented. In the ISEP section, better results can be achieved by increasing the total development area without changing the building density. If additional building land is available, additional heat consumers can be located next to the already existing developments, leading to an increase of the overall heating demand. Likewise, densification can be carried out. Applying a higher density level will increase the total heating demand as well as the heat demand density. Of course, a combination of both options is also possible. However, increasing the density is a more sustainable option than adding further building land. Whenever values of the original input data are changed or the offered scenario calculations in the EDHk are applied, associated parameters like pipe lengths, heat sources, etc. have to be adapted manually to guarantee useful results.

A decisive parameter for efficient grid systems is the connection density. For an efficient network application, the connection density in gigawatt-hour per year and kilometre pipe length should be high. The connection density also depends on the planned degree of connected buildings to the network. For instance, in one subarea of CS I only half of all buildings are connected to the DHN. In already existing structures, this might be an appropriate value; however, in order to guarantee future applicability of DHNs, operators should aim for high degrees of connection.

Another essential issue is to provide enough energy to supply all heat consumers connected to the DHN. Only if enough energy is available, good ratings in the ISEP section can be achieved. If there is not enough energy available, the utilisation of additional RES should be favoured. Increasing the use of RES will also improve the rating in the environment and climate section. Generally, the investigated CSs revealed good cost ratings. Besides the production costs of the energy sources, the connection density is again a decisive parameter in this section. For instance, by increasing the connection 
density, the $\mathrm{B}$ rating in the cost section of CS VII can be raised to $\mathrm{A}$.

\section{Discussion}

Based on the CS analyses, the discussion follows a discourse of main influencing factors and decisive parameters on DHNs. Upon that, future developments and impacts on the long-term applicability of district heating are discussed. Before reflecting the EDHk and its relevance for ISEP, possible resource utilisation of abandoned DHNs is reflected.

\section{Influencing factors and decisive parameters on the suitability of DHNs}

The CS analyses reveal heterogenous final ratings in the ISEP section. Decisive parameters posing strong influence on the final ratings across all sections mainly originate from the spatial patterns. As highlighted in the "Optimising and improving the suitability of settlements for district heating" section, efforts to identify additional heat consumers, to foster densification and to increase the degree of connected buildings are all closely related to spatial planning. Also, the connection density and the availability of energy sources strongly depend on spatial aspects. It can be summarised that most of the decisive parameters can be traced back to spatial aspects and therefore the ISEP section is also the most influential one in the EDHk. In the following, a discussion about decisive parameters concerning potential heat consumers, cost efficient DHNs and RES is presented.

The degree of connection is particularly essential for existing settlements. It refers to the share of potential heat consumers connected to the DHN. If the share is high, a better efficiency of the DHN can be reached. A low degree of connection is prone to have a negative impact on the whole DHN. For instance, Nilsson et al. [26] assume a minimum connection rate of $70 \%$ for settlements comprising detached houses. In other studies, the degree of connection is generally assumed to be $100 \%$ (see Persson and Werner [9]). It is noticeable that in new urban developments, the degree of connected buildings is high, whereas in existing settlements, it is low. Out of the eight analysed CSs, five compiled only new development areas, whereas three CSs contained both, existing and newly planned settlements. Generally, new development areas of the CS analysis comprise a high degree of connection. Yet, the overall heat demand density of the analysed settlements is calculated to be comparably low to existing settlements under the assumption of a high degree of connection, respectively. This can be explained by rather low heat demands per square metre on account of new building standards.

In the analysed CSs, the most decisive parameter in the cost section is the connection density. This parameter is simply expressed in GWh/km.a or GJ/m.a grid length. The results presented match those of Reidhav and Werner [27], where a minimum density of $2 \mathrm{GJ} /$ m.a is suggested for a DHN to be economically feasible. Conclusively, the CS analyses reveal consistent positive cost ratings across all evaluated subareas. Presumably, district heating operators aim to keep costs as low as possible. The presented results confirm this assumption, as in seven out of eight CSs, the highest rating was achieved.

Due to the national context of Austria, the evaluated CSs also induced comparatively good ratings in the environmental and climate section. The decisive driver behind the ratings is the high degree of renewable energy sources to feed the DHNs. On the contrary, only $5 \%$ of the total district heat supply worldwide originates from renewable energy sources [28]. Based on that, it is assumed that the final rating of environment and climate in the EDHk strongly depends on the national context and might reveal entirely different results in other countries.

\section{Future developments and effects on the long-term applicability of DHNs}

The presented results also include scenario calculations until 2050. In the climate change scenario, a gradual reduction of heating degree days is applied. Our analyses reveal only marginal effects on the final results. In the scientific community however, future developments of heating and cooling demand as well as the role of climate change are widely discussed [29-33]. Uncertainties and future developments concerning the long-term thermal energy demand are vital aspects in district heating planning. Due to climate change, some of the appointed research hypothesise that a reduction of heating demand could be compensated by an increase of cooling demand. However, not every grid provides the technical parameters for combined heating and cooling.

Nevertheless, slightly higher impacts on the long-term applicability of DHNs were detected after calculating the building refurbishment scenario. In this scenario, the share of refurbished buildings until 2050 are included. Yet, only few subareas were volatile to these scenario applications. Recently, Andrić et al. [34] evaluated the impacts of global warming and building refurbishments on techno-economic parameters of district heating systems. In their analysis, every decade, the whole building stock was selected for renovation. Significant impacts on DHNs were observed, after the first year of refurbishment. However, assuming a pursued refurbishment rate of only $2 \%$ in Austria [35] and comparably low rates in other European countries [36], future heat demand will only gradually decrease. Buildings of low insulation standards will continue to account for the largest proportion. 
It can be concluded that according to our calculations, not even a combination of the two scenarios until 2050 could profoundly influence the final results.

Another vital parameter for the long-term suitability of DHNs is the applied temperature level. The temperature levels in the CSs were rather low, starting at $35^{\circ} \mathrm{C}$, never surpassing $80^{\circ} \mathrm{C}$. As suggested by Lund et al. [6], reducing the temperature level of district heating is a reasonable strategy in order to guarantee long-term suitability of the networks. Low supply temperature also increases the efficiency of the heat production, subsequently resulting in a decrease of environmental pressure [37]. An additional advantage of low temperature is the reduction of heat loss within the networks.

\section{Resource utilisation of DHNs}

A crucial part of the Eco.District.Heat research project was to question the usefulness of dismantling old DHNs. Initially, the issue was raised, if the amount of material used for DHNs was sufficient to even consider dismantling. Surprisingly significant amounts of materials are used for the construction of DHNs. The main component of the networks are rocks, gravel and sand, followed by cement-bound construction materials. The material composition is essential to evaluate the usefulness of dismantling. The following conclusions from the EDH research project can be drawn. It is assumed that a dismantling and reuse of materials is only carried out if a new network is planned or other supply networks are rebuilt. Since sealed surfaces (DHNs in urban areas mostly placed along streets) have to be demolished, old supply networks will most likely stay underground. An advantage is to reactivate old networks, presuming they are still intact and fully functional. Additionally, used energy for the dismantling process has to be considered that consequently depends on the network and associated trench size. Other than that, the necessity to use synergies in order to parallelly install multiple supply networks in one trench becomes obvious. It is allegedly easier for projects currently in the planning phase, where resources could be bundled and supply infrastructure simultaneously built. For existing structures, it is a more challenging task. Once a trench is open, additional supply infrastructure could be renewed, reducing the overall environmental impact due to excavation work. If this is the case, the used energy for construction works can be split up and assigned to other supply networks like electricity or water.

\section{Strengths and limits of the Eco.District.Heat kit and its relevance for integrated spatial and energy planning}

The comprehensive approach of the EDHk has substantial value for an initial assessment of settlements concerning the suitability for DHNs. On a strategic level, it supports decision-makers to answer the question whether or not a DHN should be considered in certain urban areas. In other words, feasible locations or settlement structures regarding their suitability for implementing DHNs can be identified. This means that the same network configurations can be used and tested for different locations, in order to identify the most suitable location. If there is no possibility to change the location, the EDHk allows decision-makers to improve the applicability of DHNs at the same location. Certainly, a combination of both approaches is also possible. Besides the little time requirement for applying the methodology, the incorporated scenario calculations are another highlight of the kit, allowing users a strategic and long-term assessment. After a first assessment, carried out with the EDHk, the decision has to be taken if a detailed analysis and detailed planning of a DHN shall be performed.

Thus, detailed assessments of DHNs cannot be carried out with the kit. A critical aspect of the methodology is the dependency on the defined class boundaries. In the EDHk, a maximum of four classes in each matrix is available, so it is possible that the rating is at the upper or lower margin of the rating-class. More specifically, as a consequence of minor changes of a parameter a rating can drop or rise. Due to the isolated character of certain CSs the assessment of larger study sites revealed different results. For instance, if a single city block is connected to the grid, neighbouring blocks could also be connected, increasing the feasibility of the grid system. In that sense the effects of economies of scale have to be underlined, which allow lower prices and cost-advantages for operators due to large DHNs. Additionally, the investigated CSs mainly consist of new settlements, which might be a reason why ratings did not indicate much volatility to future scenario applications. Unfortunately, it is not possible to carry out plausible ratings in the resource section of the EDHk. This can be reasoned by the calculated absolute values for the use of materials from which it is difficult to build classes from. In fact, a rating based on used materials would always turn out to be negative, since any additional construction would adversely affect a positive rating. Thus, the lack of rating in the resource section would be a vital issue for future research. Also, diverging values from $5 \%$ up to more than $30 \%$ resource use for DHNs compared to resource use for buildings has to be questioned in the model. Here, additional validation is necessary in order to raise the certainty that this substantial amount of used materials can be allocated to DHNs. Finally, it is noteworthy that the data quality concerning the investigated CSs varied. Due to confidentiality of certain data, some data sets featured higher accuracy than others. Last but foremost, due to the many different types of urban fabrics, it was not possible to include every type in the evaluations. 
Concerning ISEP, Stoeglehner et al. [12, 38] developed essential fields of action, for which the EDHk can be utilised. With regard to these fields, the kit can support decision-makers to identify energy-efficient spatial structures, more precisely multi-functional and dense structures, and to generally reflect structures of whole settlements, also in terms of mix of function and development within settlement borders. Furthermore, the kit animates users to question the utilised energy resources, whether they are fossil or renewable. Thus, regional or potential decentral resources could be detected and employed. For instance, previously untapped heat sources like surplus thermal energy of waste water treatment plants [39-41] might be identified. In that sense, the EDHk can be used as a tool at the beginning of planning processes. Another advantage of the kit is its capability of identifying priority areas for district heating as well as grid expansion areas (see Stoeglehner et al. [12]). With regard to the spatial scale, the kit can be utilised on a municipal or settlement level. After all, the application process as well as the rating results of the EDHk might raise awareness and initiate learning processes for decision-makers. Additionally, the methodology is capable of sensitising users with regard to gaining a comprehensive view on the rather complex subject of district heating planning. In addition to that, users also acquire knowledge about the consequences of potential district heating applications. Further value is seen in the strategic character of the EDHk. Since the kit should be used prior to detailed planning, the application might save future impending costs for detailed $\mathrm{DH}$ planning. Finally, the kit also supports the identification of spatial shortcomings, especially in the presented context of ISEP. For instance, users are able to identify settlements with low building density or evaluate future scenarios and its effects on spatial parameters.

\section{Conclusions}

This study was set out to analyse and determine ideal conditions for the implementation of DHNs, by using the recently developed EDHk of Erker et al. [23]. In total, eight CSs, comprising 14 subareas, were analysed and rated. Final results present ratings in three sections: (1) integrated spatial and energy planning, (2) costs and (3) environment and climate. Heterogenous results were obtained for ISEP, whereas cost and environmental as well as climate ratings indicate rather stable results for the evaluated subareas. In dense urban areas, comprising multiple subareas, the final ISEP ratings were better compared to small or isolated and suburban settlements. Positive ratings in the cost section mainly originate from low production costs of the chosen energy sources (costs up to the feed-in point of the DHN) as well as from high occupancy rates. In the environment and climate section, the fundamental influencing factor was the share of
RES. After applying scenario calculations until 2050, it can be concluded that future developments concerning a reduction of heating degree days and an increase of refurbishment rates only reveal minor impacts on the suitability of urban areas for DH. In terms of resource utilisation of abandoned DHNs, it is apparent that although a lot of materials are used for DHNs, only under certain circumstances a dismantling of the networks is reasonable.

The main advantage of the used methodology is its strategic and interdisciplinary character, including spatial planning, environmental planning, energy technology, building technology and resource management. The kit allows users to gain a holistic perspective and to identify consequences and shortcomings of their planning proposals. Nevertheless, additional research is needed to further develop the presented methodology and to finally create a tool that can be used outside the scientific community, by urban planners, energy providers or infrastructure providers. Also, for the resource section of the kit additional development is needed in order to establish a proper rating methodology that could also be used in a final version of an "Eco.District.Heat tool".

After the comprehensive assessment of eight CSs, it can be concluded that DHSs can serve as a long-term thermal energy supply solution not only in cities but also in suburban areas. Although population growth and future housing developments were not directly integrated in the CS comparisons, growing cities and continuous influx into cities [42] will presumably increase the overall thermal energy demand in urban areas. Similarly, development of city and town centres and densification, both main pillars of ISEP, will further increase heat demand densities. Moreover, most urban fabrics consist of both existing and new buildings. The result is a composition of different heat demands of individual buildings within the same urban area. For instance, heat demand of recently built multi-storey buildings is comparably low, starting at $10 \mathrm{kWh} / \mathrm{m}^{2}$ a whereas old unrenovated buildings (1920-1960) require up to $270 \mathrm{kWh} / \mathrm{m}^{2} \mathrm{a}$ [43]. Due to low refurbishment rates, we additionally assume that there will be little significant influence on the long-term suitability of DHNs.

On the contrary, under the assumption of prospective low space heating demand, the importance of domestic hot water will presumably increase. For upcoming generations of district heating, Lund et al. [44] underline the possible scenario of reducing space heating demand to a level equivalent to that of domestic hot water demand. Since domestic hot water use is quite constant during the course of a year, a better balance across seasons can be reached. Moreover, energy efficient buildings like plus energy houses are capable of being energy self-sufficient and even produce surplus energy throughout the year. Although the 
importance of domestic hot water demand will likely increase, seasonal fluctuations (higher heat demand in winter) will remain. Thus, DH can be used to cover the base load and excess heat produced of plus energy buildings can be fed into the DHN. By integrating such decentral solutions and adding prosumers to feed the system, additional future potentials can develop and the use of renewable energy sources can be increased.

\section{Abbreviations}

AEA: Austrian Energy Agency; CS: Case study; DH: District heating;

DHN: District heating network; DHS: District heating system;

EDH: Eco.District.Heat; EDHk: Eco.District.Heat kit; GDA: Gross development area; GFA: Gross floor area; GIS: Geographic information system;

IRUB: Institute of Spatial Planning, Environmental Planning and Land Rearrangement, University of Natural Resources and Life Sciences, Vienna; ISEP: Integrated spatial and energy planning; RES: Renewable energy source; RMA: Resource management agency

\section{Acknowledgements}

The authors want to thank the project partners and the advisory board members of the research project "Eco.District.Heat" for the continuous support. Findings, conclusions and recommendations within this paper reflect results of the original study.

\section{Funding}

This paper is based on findings from the project "Eco.District.Heat - Potenziale und Restriktionen leitungsgebundener Wärmeversorgung in Stadtquartieren (Project No 854673). The project is funded by the Austrian Ministry of Transport, Innovation and Technology (BMVIT) within the programme "Stadt der Zukunft" of the Austrian Research Promotion Agency (FFG). Due to funding regulations, we are instructed to include the following phrasing: Stadt der Zukunft ist ein Forschungs- und Technologieprogramm des Bundesministeriums für Verkehr, Innovation und Technologie. Es wird im Auftrag des BMVIT von der Österreichischen Forschungsförderungsgesellschaft gemeinsam mit der Austria Wirtschaftsservice Gesellschaft mbH und der Österreichischen Gesellschaft für Umwelt und Technik ÖGUT abgewickelt". The funding body had no role in data collection, analysis, and interpretation of data as well as in writing the manuscript.

\section{Availability of data and materials}

Original data provided by external institutions are not publicly available due to their respective data protection regulations. Selected analysed data are available from the corresponding author upon reasonable request, as long as it does not contradict the insitutions' data protection regulations. Additional information concerning the used methodology, the Eco.District.Heat-kit and further findings of the research project "Eco.District.Heat" can be found in Erker et al. (2019): "Interdisciplinary decision support model for grid-bound heat supply systems in urban areas", in (Zach F, Erker S, Stoeglehner G: Factors influencing the environmental and economic feasibility of district heating systems - a perspective from integrated spatial and energy planning, unpublished) and in the "Eco.District.Heat" project reports.

\section{Authors' contributions}

PL carried out the case study analysis and took a lead in the write-up of the article. SE led the development of the used methodology, the "Eco.District.Heat" kit, and supported the case study analysis. FZ contributed with his expert knowledge concerning technical, economic and energetic aspects of heat supply systems. GS coordinated the research project Eco.District.Heat, contributed knowledge to integrated spatial and energy planning as well as to the development of planning and assessment methods. He took a lead in conceptualising and revising the paper. All authors read and approved the final manuscript.

\section{Ethics approval and consent to participate}

Not applicable.

\section{Consent for publication}

Not applicable.

\section{Competing interests}

The authors declare that they have no competing interest.

\section{Publisher's Note}

Springer Nature remains neutral with regard to jurisdictional claims in published maps and institutional affiliations.

\section{Author details}

${ }^{1}$ Institute of Spatial Planning, Environmental Planning and Land Rearrangement, University of Natural Resources and Life Sciences, Vienna, Peter-Jordan-Straße 82, 1190 Vienna, Austria. ${ }^{2}$ Austrian Energy Agency, Mariahilfer Straße 136, 1150 Vienna, Austria.

Received: 10 October 2018 Accepted: 19 February 2019

Published online: 29 March 2019

\section{References}

1. UNFCCC (2015) Paris Agreement. United Nations Framework Convention on Climate Change, Paris.

2. Burck J, Marten F, Bals C, Höhne N, Frisch C, Clement N, Kao S-C (2017) The climate change performance index results 2018. Germanwatch, Bonn.

3. EC (2015) Report from the Commission to the European Parliament, the Council, the European Economic and Social Committee and the Committee of the Regions. In: Renewable energy progress report, COM(2015) 293 final on 15.6.2015. European Commission, Brussels.

4. EC (2016) Report from the Commission to the European Parliament, the Council, the European Economic and Social Committee and the Committee of the Regions. In: An EU strategy on heating and cooling, COM(2016) 51 final on 16.2.2016. European Commission, Brussels.

5. BMNT (2017) Erneuerbare Energie in Zahlen 2017 - Entwicklung in Österreich. Bundesministerium für Nachhaltigkeit und Tourismus, Wien.

6. Lund R, Østergaard DS, Yang X, Mathiesen BV (2017) Comparison of lowtemperature district heating concepts in a long-term energy system perspective. Int J Sustain Energy Plann Manag 12:5-18. https://doi.org/10. 5278/ijsepm.2017.12.2.

7. Carpaneto E, Lazzeroni P, Repetto M (2015) Optimal integration of solar energy in a district heating network. Renew Energy 75:714-721. https://doi. org/10.1016/j.renene.2014.10.055.

8. Lichtenegger K, Wöss D, Halmdienst C, Höftberger E, Schmidl C, Pröll T (2017) Intelligent heat networks: first results of an energy-information-costmodel. Sustain Energy Grids Netw 11:1-12. https://doi.org/10.1016/j.segan. 2017.05.001.

9. Persson U, Werner S (2011) Heat distribution and the future competitiveness of district heating. Appl Energy 88:568-576. https://doi.org/ 10.1016/j.apenergy.2010.09.020

10. Narodoslawsky M (2014) Utilising bio-resources: rational strategies for a sustainable bio-economy. Austrian Academy of Sciences, Vienna.

11. Stoeglehner $G$, Emrich $H$, Koch $H$, Narodoslawsky M (2017) Impulse für eine kommunale Energieraumplanung. Bundesministerium für Land- und Forstwirtschaft, Umwelt und Wasserwirtschaft, Wien.

12. Stoeglehner G, Neugebauer G, Erker S, Narodoslawsky M (2016) Integrated spatial and energy planning - supporting climate protection and the energy turn with means of spatial planning. Springer International Publishing, Cham.

13. Neugebauer G, Kretschmer F, Kollmann R, Narodoslawsky M, Ertl T, Stoeglehner G (2015) Mapping thermal energy resource potentials from wastewater treatment plants. Sustainability 7:12988-13010. https://doi.org/ 10.3390/su71012988.

14. Mathiesen BV, Drysdale DW, Lund H, Paardekooper S, Skov IR, Conolly D, Thellufsen JZ, Jensen JS (2016) Future green buildings: a key to costeffective sustainable energy systems. Department of Development and Planning, Aalborg University, Aalborg.

15. Loibl W, Stollnberger R, Österreicher D (2017) Residential heat supply by waste-heat re-use: sources, supply potential and demand coverage—a case study. Sustainability 9:250. https://doi.org/10.3390/ su9020250.

16. EC (2011) Communication from the Commission to the European Parliament, the Council, the European Economic and Social Committee and the Committee of the Regions. In: Roadmap to a resource efficient europe, COM(2011) 571 final on 20.9.2011. European Commission, Brussels. 
17. Stoeglehner G, Erker S, Neugebauer G (2014) Tools für Energieraumplanung. Ein Handbuch für deren Auswahl und Anwendung im Planungsprozess. Bundesministerium für Land- und Forstwirtschaft, Umwelt und Wasserwirtschaft, Wien.

18. Hegger M, Dettmar J (2014) Energetische Stadtraumtypen: strukturelle und energetische Kennwerte von Stadträumen. Fraunhofer IRB Verlag, Stuttgart.

19. StMUG (2010) Leitfaden Energienutzungsplan - Teil1 Bestands- und Potenzialanalyse. Bayerisches Staatsministerium für Umwelt und Gesundheit, München.

20. Kleemann F, Lederer J, Rechberger H, Fellner J (2017) GIS-based analysis of Vienna's material stock in buildings: GIS-based analysis of material stock in buildings. J Ind Ecol 21:368-380. https://doi.org/10.1111/jiec.12446.

21. Rossi B, Marique A-F, Glaumann M, Reiter S (2012) Life-cycle assessment of residential buildings in three different European locations, basic tool. Build Environ 51:395-401. https://doi.org/10.1016/j.buildenv.2011.11.017.

22. Werner S (2017) International review of district heating and cooling. Energy 137:617-631. https://doi.org/10.1016/j.energy.2017.04.045.

23. Erker S, Lichtenwoehrer P, Zach F, Stoeglehner G (2019) Interdisciplinary decision support model for grid-bound heat supply systems in urban areas. JESS. https://doi.org/10.1186/s13705-019-0193-4.

24. Exner A, Politti E, Schriefl E, Erker S, Stangl R, Baud S, Warmuth H, Matzenberger J, Kranzl L, Paulesich R, Windhaber M, Supper S, Stöglehner G (2016) Measuring regional resilience towards fossil fuel supply constraints. Adaptability and vulnerability in socio-ecological transformations-the case of Austria. Energy Policy 91:128-137. https:/doi.org/10.1016/j.enpol.2015.12.031.

25. Stoeglehner G, Niemetz N, Kettl K-H (2011) Spatial dimensions of sustainable energy systems: new visions for integrated spatial and energy planning. Energy Sustain Soc 1:2. https://doi.org/10.1186/2192-0567-1-2.

26. Nilsson SF, Reidhav C, Lygnerud K, Werner S (2008) Sparse district-heating in Sweden. Appl Energy 85:555-564. https://doi.org/10.1016/j.apenergy.2007.07.011.

27. Reidhav C, Werner S (2008) Profitability of sparse district heating. Appl Energy 85:867-877. https://doi.org/10.1016/j.apenergy.2008.01.006.

28. IRENA (2017) Renewable energy in district heating and cooling: a sector roadmap for REmap. International Renewable Energy Agency, Abu Dhabi.

29. Isaac M, van Vuuren DP (2009) Modeling global residential sector energy demand for heating and air conditioning in the context of climate change. Energy Policy 37:507-521. https://doi.org/10.1016/j.enpol.2008.09.051.

30. Li DHW, Yang L, Lam JC (2012) Impact of climate change on energy use in the built environment in different climate zones-a review. Energy 42:103112. https://doi.org/10.1016/j.energy.2012.03.044.

31. Berger T, Amann C, Formayer H, Korjenic A, Pospischal B, Neururer C, Smutny R (2014) Impacts of climate change upon cooling and heating energy demand of office buildings in Vienna, Austria. Energy Build 80:517530. https://doi.org/10.1016/j.enbuild.2014.03.084

32. Jylhä K, Jokisalo J, Ruosteenoja K, Pilli-Sihvola K, Kalamees T, Seitola T, Mäkelä HM, Hyvönen R, Laapas M, Drebs A (2015) Energy demand for the heating and cooling of residential houses in Finland in a changing climate. Energy Build 99:104-116. https://doi.org/10.1016/j.enbuild.2015.04.001.

33. Werner S (2016) European space cooling demands. Energy 110:148-156. https://doi.org/10.1016/j.energy.2015.11.028.

34. Andrić I, Fournier J, Lacarrière B, Le Corre O, Ferrão P (2018) The impact of global warming and building renovation measures on district heating system techno-economic parameters. Energy 150:926-937. https://doi.org/ 10.1016/j.energy.2018.03.027.

35. BMNT, BMVIT (2018) \#mission2030 - Die österreichische Klima- und Energiestrategie. Bundesministerium für Nachhaltigkeit und Tourismus and Bundesministerium für Verkehr, Innovation und Technologie, Wien.

36. Enerdata (2018) ZEBRA2020 - Data Tool. http://www.zebra-monitoring. enerdata.eu. Accessed 1 Aug 2018.

37. Sayegh MA, Danielewicz J, Nannou T, Miniewicz M, Jadwiszczak P, Piekarska K, Jouhara H (2017) Trends of European research and development in district heating technologies. Renew Sust Energ Rev 68:1183-1192. https:// doi.org/10.1016/j.rser.2016.02.023.

38. Stoeglehner G, Erker S, Neugebauer G (2014) Energieraumplanung. Materialienband. Zusammenarbeit mit der ÖREK-Partnerschaft "Energieraumplanung". Auftraggeber und Leadpartner: Bundesministerium für Land- und Forstwirtschaft, Umwelt und Wasserwirtschaft, Medieninhaber und Herausgeber: Geschäftsstelle der Österreichischen Raumordnungskonferenz (ÖROK), ÖROK Schriftenreihe Nr. 192, Wien.

39. Neugebauer G, Stöglehner G (2015) Realising energy potentials from wastewater by integrating spatial and energy planning. Sustain Sanitation Pract 22:15-21.
40. Kretschmer F, Neugebauer G, Kollmann R, Eder M, Zach F, Zottl A, Narodoslawsky M, Stoeglehner G, Ertl T (2016) Resource recovery from wastewater in Austria: wastewater treatment plants as regional energy cells. J Water Reuse Desalination 6:421-429. https://doi.org/10.2166/wrd.2015.119.

41. Kollmann R, Neugebauer $G$, Kretschmer F, Truger B, Kindermann $H$, Stoeglehner G, Ertl T, Narodoslawsky M (2017) Renewable energy from wastewater - practical aspects of integrating a wastewater treatment plant into local energy supply concepts. J Clean Prod 155:119-129. https://doi. org/10.1016/j.jclepro.2016.08.168

42. United Nations (2018) World urbanization prospects: the 2018 revision. https://population.un.org/wup/Publications/Files/WUP2018-KeyFacts.pdf. Accessed 25 July 2018.

43. Amtmann M, Groß M (2011) Eine Typologie Österreichischer Wohngebäude. Austrian Energy Agency, Wien.

44. Lund H, Werner S, Wiltshire R, Svendsen S, Thorsen JE, Hvelplund F, Mathiesen BV (2014) 4th generation district heating (4GDH): integrating smart thermal grids into future sustainable energy systems. Energy 68:1-11. https://doi.org/10.1016/j.energy.2014.02.089.

\section{Ready to submit your research? Choose BMC and benefit from:}

- fast, convenient online submission

- thorough peer review by experienced researchers in your field

- rapid publication on acceptance

- support for research data, including large and complex data types

- gold Open Access which fosters wider collaboration and increased citations

- maximum visibility for your research: over $100 \mathrm{M}$ website views per year

At BMC, research is always in progress.

Learn more biomedcentral.com/submissions 